\title{
The role of microRNA in metastatic colorectal cancer and its significance in cancer prognosis and treatment
}

\author{
Paulina Tokarz and Janusz Blasiak ${ }^{\bowtie}$ \\ Department of Molecular Genetics, Faculty of Biology and Environmental Protection, University of Lodz, Łódź, Poland
}

microRNAs (miRNAs) are small, non-coding RNA molecules that regulate gene expression by targeting specific mRNAs. microRNAs play a role in several physiological processes in the cell, including migration, proliferation, differentiation and apoptosis. Apart from their role in regular metabolism, abnormal profiles of miRNA expression accompany cancer transformation, including colorectal cancer (CRC) metastasis. microRNAs may play a role in each phase of CRC metastasis including angiogenesis, invasion, intravasation, circulation, extravasation and metastatic colonization. microRNA levels may serve as a predictive CRC marker, which was confirmed by the serum level of miR-29a targeting KLF4, a marker of cell stemness, and the plasma level of miR-221 downregulating c-Kit, Stat5A and ETS1, which are signal transducers and transcription factor, respectively. In turn, the level of miR-143 in CRC cells decreasing the amount of MACC1 (metastasis-associated in colon cancer-1) and oncogenic KRAS protein, may be utilized as a prognostic marker. Also, single nucleotide polymorphisms of genes encoding miRNAs, including miR-423 and miR-608, which correlate with tumor recurrence, may be useful as diagnostic, prognostic and predictive indicators in CRC metastasis. Pre-miR-34a and pre-miR-199a decreased the level of Axl, a tyrosine-protein kinase receptor, so they can be considered as drugs in antimetastatic therapy. On the other hand, miR-222 targeting ADAM-17, a disintegrin and metalloproteinase, and miR-328 interacting with $A B C G 2$, an $A B C$ transporter, may overcome drug resistance of cancer cells. microRNAs may be considered in wide-range application to facilitate CRC metastasis diagnosis, prognosis, prediction and therapy, however, further clinical, epidemiological and in vitro studies should be conducted to verify their utility.

Key words: colorectal cancer, metastasis, miRNA, prediction, prognosis, therapy

Received: 31 October, 2012; accepted: 17 November, 2012; avialable on-line: 21 November, 2012

\section{INTRODUCTION}

Colorectal cancer (CRC) has one of the highest rates of morbidity and mortality worldwide. Approximately 1.23 million of CRCs are diagnosed yearly worldwide and 0.6 million CRC patients died of it in 2008 (Ferlay et al., 2010). Metastasis in CRC is the prime cause of death of patients with this disease. Metastasis is a multistep process of cell spread from the primary tumor to non-adjacent organs and formation of a secondary tumor. This process includes growth of the primary can- cer, angiogenesis, invasion of cancer cells, intravasation into lymphatic/blood vessels, extravasation into a distant organ and colonization and growth of metastatic tumors. Since treatment of CRC in its non-metastatic phase increases the survival rate, an insight into molecular pathways of CRC metastasis may be important for developing new prognostic and predictive molecular markers facilitating the reduction of CRC metastates. The emerging perspective of anticancer treatment is the utilization of microRNA (miRNA) (Zheng et al., 2010a). microRNAs are small, endogenous, regulatory RNA molecules that modulate expression of their target genes. They are conserved in evolution and may play a role in physiologi$\mathrm{cal}$ and pathological processes including CRC metastasis by influencing cancer-stem-cell biology, angiogenesis, the epithelial-mesenchymal and mesenchymal-epithelial transition or drug resistance (Bhardwaj et al., 2010). Aberration in the expression of miRNA accompanies the progression of CRC (Vickers et al., 2012). This effect may be underlined by deletions, amplifications or point mutations of miRNA loci, epigenetic silencing, deregulation of transcription factors - modifiers of miRNA expression or inhibition of processing of primary miRNA to its mature form (Ha, 2011). Applying miRNAs in anticancer therapy could be efficient since single miRNA can modulate the expression of various genes (Muniyappa et al., 2009).

\section{BIOGENESIS OF MIRNA}

microRNA is a non-coding, small RNA molecule consisting of 22 nucleotides on average, found in eukaryotic cells. microRNA genes are transcribed primarily by RNA polymerase II producing a molecule of hundreds of nucleotides in length, which is called primary miRNA (pri-miRNA) (Lee et al., 2004) (Fig. 1). Typically, the re-

e-mail: jblasiak@biol.uni.lodz.pl

Abbreviations: ADAM: a disintegrin and metalloproteinase; Cdc42 cell division control protein 42 homolog; CRC: colorectal cancer; DAPK: death-associated protein kinase 1; EGFR: epithelial growth factor receptor; EMT: epithelial to mesenchymal transition; ETS1: v-ets erythroblastosis virus E26 oncogene homolog 1; hMSH2: human mutS homolog 2; hMSH6: human mutS homolog 6; HUVEC: human umbilical vein endothelial cells; IGF1-R: insulin-like growth factor 1 receptor gene; KLF4: Krüppel-like factor 4; KRAS: V-Ki-ras2 Kirsten rat sarcoma viral oncogene homolog; MDR: multidrug-resistant; miRNA: microRNA; miRISC: miRNA-associated RNA-induced silencing complex; PDCD4: programmed cell death; 4PI3K: phosphatidylinositol-3-kinase; pre-miRNA: precursor miRNA; pri-miRNA: primary miRNA; Scrib: Scribble protein; SNP: single nucleotide polymorphism; SP: side population; TSP-1: thrombospondin-1; 3'UTR: 3'-untranslated region; 5-FU: 5-fluorouracil; VEGF: vascular endothelial growth factor; VCAM-1: vascular cell adhesion molecule 1; ZEB1: zinc finger E-box binding homeobox 1. 
sulting transcript has a cap at the $5^{\prime}$ end and a poly(A) tail at the 3' end and is spliced. To yield the functional mature miRNA, several post-transcriptional processing steps are required. Pri-miRNA forms a stem loop which is recognized by the DGCR8 (DiGeorge Syndrome Critical Region 8) protein associated with the Drosha enzyme that processes pri-miRNA into a double-stranded (ds) hairpin structure of approximately 70 nucleotides in length, which is termed precursor miRNA (pre-miRNA) (Lee et al., 2003; Han et al., 2004). Then, pre-miRNA is exported from the nucleus to the cytoplasm by the Exportin-5 and Ran proteins in a GTP-dependent manner (Bohnsack et al., 2004). In the cytoplasm, pre-miRNA is cleaved into dsRNAs by the Dicer RNaseIII enzyme. One strand of dsRNA is degraded, this strand is usually denoted miRNA*, and the other, mature single-stranded (ss) miRNA, forms the miRNA-associated RNA-induced silencing complex (miRISC) (Gregory et al., 2005). The degradation of the miRNA strand is nonrandom but the reason for this specificity is unknown. microRNA in miRISC may influence gene expression by binding to the 3'-untranslated region (3'-UTR) in the target mRNA. This region consists of sequences recognized by miRNA, while miRNA comprises a region of 2-8 nucleotides at its $5^{\prime}$ end, called the seed region that determines its specificity and binds to mRNA at its 3'-UTR (Bartel, 2009; Lewis et al., 2005). If the complementarity of the miRNA:mRNA complex is perfect, the mRNA is degraded by Ago2, a protein belonging to the Argonaute family. However, if the complementarity is not perfect, the translation of the target mRNA is suppressed. To date, more than 1900 human mature miRNAs have been identified (http://www.miRbase.org/index.shtml), which

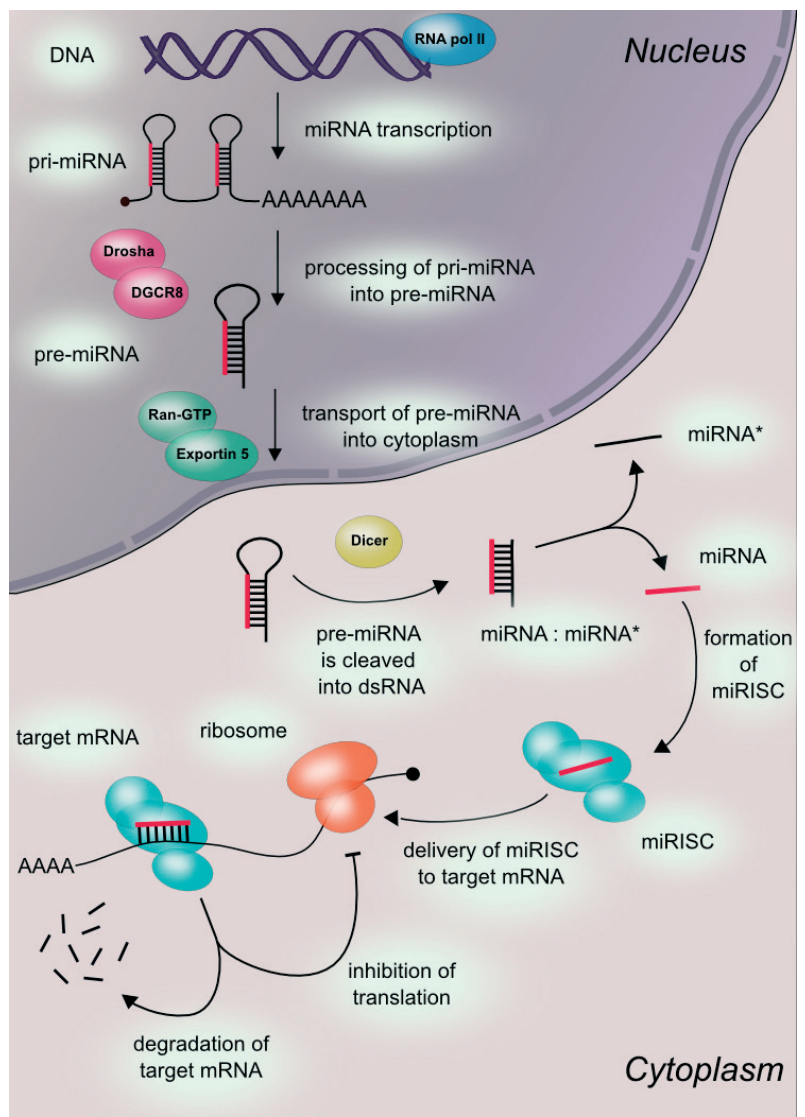

Figure 1. Schematic representation of microRNA (miRNA) biogenesis and function. are estimated to regulate more than $10 \%$ of all protein coding genes.

\section{MICRORNA IN CANCER TRANSFORMATION}

Carcinogenesis is a complex process occurring in a stepwise manner, including primary tumor initiation, promotion and progression. Tumor progression leads to the creation of blood vessels in the proximity of the tumor, cancer cell detachment from the tumor mass, migration and invasion, through cancer cell intravasation, transport through circulation, extravasation to the ultimate formation of secondary tumor(s) located distant from the primary progenitor.

\section{Angiogenesis}

The formation of a network of blood vessels, angiogenesis, near the tumor is essential for its growth and contact of the cancer with the bloodstream. Angiogenesis is regulated by pro- and anti-angiogenic factors (Jain, 2005). The results of studies indicate that miRNA may exert pro-angiogenic or anti-angiogenic effects thus regulating angiogenesis (Poliseno et al., 2006; Bonauer et al., 2009). miR-194 modulated the expression level of THBS1, which encodes thrombospondin-1 (TSP-1), an endogenous inhibitor of angiogenesis, in the HTC116 CRC cell line (Sundaram et al., 2011). miR-194 bound to the complementary sequence on mRNA of THBS1 resulting in an increased microvascular density, vessel size and angiogenesis. miR-221 and miR-222 are frequently and highly expressed in CRC, which correlated with TNM stage and local invasion (Sun et al., 2011; Ota et al., 2012). Both miR-221 and miR-222 inhibited the angiogenic activity by targeting the mRNA of c-Kit (v-kit Hardy-Zuckerman 4 feline sarcoma viral oncogene homolog), Stat5A (signal transducer and activator of transcription 5A), endothelial nitric oxide synthase and ETS1 (v-ets erythroblastosis virus E26 oncogene homolog 1) in HUVEC (human umbilical vein endothelial cells) (Poliseno et al., 2006; Dentelli et al., 2010; Suárez et al., 2007; Zhu et al., 2011). The polycistronic miR-17-92 cluster, also denoted as Oncomir-1, contains six precursor-sequence members (Tanzer \& Stadler, 2004). Pre-miR-17 is the precursor of both miR-17 and of miR-91. The other members of this cluster are miR-18, miR-19, miR19b, miR-20, and miR-92. Oncomir-1 enhanced tumor angiogenesis by targeting a number of anti-angiogenic targets in various cancers (Bonauer et al., 2009). The proangiogenic function of these miRNAs was attributed to the down-regulation of the mRNA of TSP-1 and CTGF (connective tissue growth factor), which were targeted by miR-18 and miR-19 in myc-transfection-induced CRC tumors (Dews et al., 2006). The expression of the miR17-92 cluster was significantly higher in CRC patients than in the control group (Koga et al., 2010; Chang et al., 2011). A few miR-17-92 targets were reported to be deregulated in CRC (Humphreys et al., 2012) and only two of them, PTEN (phosphatase and tensin homolog) and BCL2L11 (Bcl-2-like protein 11), may have a role in angiogenesis in CRC. PTEN is a phosphatase related to the phosphatidylinositol-3-kinase (PI3K) pathway which regulates angiogenesis in endothelial cells (Rodriguez \& Huynh-Do, 2012). BCL2L11 is a pro-apoptotic factor and its inhibition led to endothelial cell apoptosis which is essential mechanism of angiogenesis (Chavakis \& Dimmeler, 2002). However, over-expression of only one miRNA from the miR-17-92 cluster, miR-92a, had an anti-apoptotic effect (Bonauer et al., 2009). In human 
endothelial cells an increased level of miR-92a blocked sprout formation, inhibited vascular network formation, reduced epithelial cell migration and impaired cell adhesion to fibronectin. miR-126 was expressed specifically in epithelial cells where it modulated the expression of sprouty-related protein SPRED1 and PIK3R2 (PI3K regulatory subunit 2) thus promoting VEGF (vascular endothelial growth factor) signaling in response to angiogenic growth factors (Fish et al., 2008; Wang et al., 2008). miR-126 loss in mice caused the loss of vascular integrity and defects in endothelial cell proliferation, migration and angiogenesis. Apart from these results, down-regulation of miR-126 was noted in primary CRC relative to normal adjacent mucosa (Schepeler et al., 2012; Guo et al., 2008). Reintroduction of miR-126 inhibited CRC cell growth in vitro. The target of miR-126 was mRNA of p85beta (phosphatidylinositol-3-kinase regulatory subunit beta), a regulatory subunit involved in stabilizing and propagating the PI3K signal (Guo et al., 2008). It is hypothesized that down-regulation of miR-126 could abolish check point of p85beta by increasing the p85beta level contributing to the amplification of PI3K signal. An up-regulated level of miR-210 was noted in CRC patients with accompanying KRAS (V-Ki-ras2 Kirsten rat sarcoma viral oncogene homolog) mutation (Ota et al., 2012). miR-210 is a hypoxia-induced miRNA whose over-expression stimulated angiogenesis and migration of epithelial cells, while inhibition of miR-210 decreased hypoxia-induced tube formation in these cells (Fasanaro et al., 2008). miR-497 is a suppressor of the insulin-like growth factor 1 receptor gene (IGF1-R) (Guo et al., 2012). IGF1-R was found to exert favorable effects on angiogenesis (Dobrucki et al., 2010). Down-regulation of IGF1-R by miR-497 in CRC cells compared to normal mucosa was associated with inhibition of cell survival, proliferation, invasion, and increased sensitivity to apoptosis, thus down-regulation of miR-497 may contribute to angiogenesis (Guo et al., 2012). miR-296 was lost in $86 \%$ (13 out of 16) of CRC tumors (Vaira et al., 2012). One of the miR-296 targets is mRNA of Scribble protein (Scrib). The loss of miR-296 and subsequent elevated level of Scrib inhibited cell migration and invasion. Re-expression of miR-296 inhibited tumor growth in vivo. An elevated level of miR-424 was observed in CRC cell lines and in CRC tumors compared with normal colorectal samples, which may be a result of hypoxia-induced deregulation of its expression (Wang et al., 2012b; Ghosh et al., 2010). Increased level of miR-424 led to activation of genes governing angiogenesis (Ghosh et al., 2010).

It seems that miRNA may exert distinct roles in CRC angiogenesis through regulation of the level of mRNA encoding inhibitors or activators of angiogenesis. Apart from the changes of miRNA level accompanying angiogenesis, which could serve for early CRC diagnosis, some miRNAs were reported to exert a therapeutic effect such as miR-126, miR-497 or miR-296. Interestingly, there may be a link between genetic and epigenetic aberrations since a $K R A S$ mutation induced over-expression of miR-210 in a DLD-1 colorectal cancer cells in threedimensional culture.

\section{CANCER CELL INVASION}

Cancer cell invasion from the tumor mass to adjacent tissue is an early step in tumor progression. This process includes directional activation of proteolytic enzymes, including metalloproteases, degradation of extracellular matrix, transition of the cancer phenotype from epithelial to mesenchymal (EMT) and translocation of cancer cells. The elevated level of miR-31 is attributed to the invasive nature of CRC cells in vitro and in vivo (Wang et al., 2010; Chang et al., 2011). The level of miR-122 was increasing from non-neoplastic tissue to dysplasia, but decreasing from dysplasia to inflammatory bowel disease-associated CRC (Kanaan et al., 2012). The deregulation of the miR200 family was associated with acquiring an aggressive phenotype. Hypomethylation of the miR-200c promoter region resulted in an increase in miR-200c expression and was up-regulated in CRC liver metastates compared to primary CRC (Hur et al., 2012). Transfection with pre-miR-200c resulted in an enhanced cell proliferation, but reduced invasion and migration of CRC cell lines. It reduced the expression of the miR-200c target genes: ZEB1 (zinc finger E-box binding homeobox 1), ETS1 and FLT1 (fms-related tyrosine kinase 1) and resulted in increased E-cadherin and reduced vimentin levels. Thus, miR-200c may play an important role in mediating EMT and metastatic behavior in CRC. Studies conducted on CRC cell lines showed that over-expression of SIX1 repressed CDH1 expression and promoted EMT in CRC partly through repression of miR-200-family expression and activation of ZEB1 (Ono et al., 2012). In CRC, a reduction of miR-328 expression accompanied a high fraction of side population (SP) cells showing cancer stemlike properties (Xu et al., 2012b). The level of miR-328 was relatively higher in non-SP cells compared with SP cells. The over-expression of miR-328 inhibited cell invasion of SP cells. The direct targets of miR-328 were mRNAs of the ABCG2 (ATP-binding cassette sub-family $G$ member 2) protein and MMP16 (matrix metalloproteinase-16). miR-143 and miR-145 showed reduced levels in CRC tumor samples and were undetected in CRC cell lines (Arndt et al., 2009). miR-143 targeted MACC1 (metastasis-associated in colon cancer-1) — a newly identified gene which is highly expressed in CRC and promotes tumor metastasis through trans-activating metastasis-inducing HGF/MET signaling pathway (Boardman, 2009). Restoration of miR-143 in SW620 CRC cells attenuated cell growth, migration and invasion (Arndt et al., 2009). Conversely, reduction of miR-143 stimulated these phenotypes. Expression of miR-145 in SW620/ miR-145 cell line at a level similar to that observed in normal colon epithelial cells led to effects typical for a mesenchymal-like phenotype: an elongated cell shape, reduced level of E-cadherin and increased cell proliferation and metabolism. An over-expression of miR-103 and miR-107 was observed in CRC tumor cells and was stimulated in the presence of hypoxia (Chen et al., 2012). The miR-103 and miR-107 directly targeted mRNAs of DAPK (death-associated protein kinase 1) or KLF4 (Krüppel-like factor 4), respectively, which resulted in an increased cell motility and cell-matrix adhesion and decreased cell-cell adhesion as well as epithelial marker expression. In CRC mouse models, a miR-103/107 elevated level promoted local invasion and liver metastasis. These effects were inhibited by miR-103/107-mediated re-expression of $D A P K$ and KLF4. The expression of miR-29a was elevated in CRC tumor samples compared to normal epithelial tissue accompanying the down-regulation of its target gene, KLF4, expression ( $\mathrm{Fu}$ et al., 2012; Huang et al., 2010). KLF4 is associated with cell cycle arrest and its level is influenced by several factors, including miR-29a (Zhao et al., 2004; Fu et al., 2012). Mir-29a was a specific and sensitive marker discriminating CRC with liver metastates from non-metastatic CRC (Wang et al., 2012a). The over-expression of miR-21 is frequently observed in CRC (Fu et al., 2012; Faltejskova 
et al., 2012). miR-21, miR-17 and miR-19a-induced expression by PRL-3 (phosphatase of regenerating liver-3) - encoded by an oncogene promoting tumor metastasis - favored cell proliferation and CRC metastasis (Zhang et al., 2012a). miR-21 targets mRNAs of a number of tumor suppressor genes including PDCD4 (programmed cell death 4), CCL20 (chemokine (C-C motif) ligand 20) and $C d c 25 A$ (cell division cycle 25 homolog A), but not PTEN in CRC (Asangani et al., 2008; Vicinus et al., 2012; Wang et al., 2009; Vickers et al., 2012). A higher expression of miR-21 correlated with a decreased level of PDCD4 in dysplasia and invasive CRC (Fassan et al., 2011). Suppression of miR-21 decreased cell migration ability of DLD-1 CRC cells (Faltejskova et al., 2012). Also epidermal growth factor (EGF)/Ras efficiently increased the miR-21 transcription, but not the mature miR-21 level. However, Pea3 (E-twenty six factor ets variant 4) repressed miR-21 transcription (Kern et al., 2012).

The phenotype of cancer cells may be influenced by shifts in the expression of miRNA, such as miR-122, leading to cancer cell spread to adjacent regions. microRNA may play a role in acquiring stem-cell-like properties by cancer cells or regulating EMT. The latter was demonstrated by the effect of down- or up-regulation of miR-200 family and downstream increase/decrease of ZEB1 level and stimulation/repression of EMT, accordingly. The control of the miR-200c expression was carried out, at least partially, through DNA methylation, showing cooperation between these epigenetic mechanisms. microRNA expression may also be regulated by other factors such as the concentration of oxygen in tissue. The hypoxia-stimulated over-expression of miR103 and miR-107 led to a decrease in KLF4, which promoted CRC invasion. The decrease in the KLF4 level may be due to a joint action of miR-103, miR-107 and miR-29a, indicating synergistic effects of gene silencing by RNA interference.

\section{INTRAVASATION, CIRCULATION AND EXTRAVASATION}

The exact mechanism of cancer cell dissociation from tumor mass, passing through the basement membrane and reaching the blood/lymph vessels in CRC is elusive. Despite the fact that these mechanisms are complex and not fully understood, some studies elucidating this issue were conducted. It was reported that miR-21 might play a role in intravasation through down-regulation of the tumor suppressor Pdcd4 (Asangani et al., 2008). A higher expression of miR-21 was noted in metastatic than in non-metastatic CRC and miR-21 was associated with lymph node metastasis (Vickers et al., 2012; Slaby et al., 2007). Up-regulation of miRNA-21 led to initiation of tumor formation but also increased cancer invasion, intravasation and metastatic potential (Asangani et al., 2008; Wang et al., 2009a). Thus, miRNA is supposed to control CRC metastasis at least at the level of tumor growth, invasion and intravasation.

Cancer cells which enter the bloodstream are exposed to shear stress and attack from the immune system which may result in cancer cell degradation (Bockhorn et al., 2007). A number of miRNAs have been discovered to play critical roles in modulation of $\mathrm{T}$ and $\mathrm{B}$ lymphocyte activation, innate and adaptive immune responses (Lu \& Liston, 2009). The studies on epithelial model cells, HUVEC, showed that expression of miR-126 inhibited VCAM-1 (vascular cell adhesion molecule 1) expression (Harris et al., 2008). VCAM-1 is an adhesion molecule expressed on the surface of dividing epithelial cells, which mediates leukocyte adherence to these cells, promoting inflammation. The results of that study demonstrated an inverse correlation between miR-126 and VCAM-1 expression. miR-155 is required for adaptive and innate immunity and miR-17-92 cluster for adaptive differentiation of B cells and conventional T cells ( $\mathrm{Lu} \&$ Liston, 2009). Although the exact role of miRNA in cancer cell intravasation is unknown, it seems that miRNA helps cancer cells to evade recognition by the immune system in the blood/lymph vessels.

The escape of cancer cells from capillaries to invade the parenchyma is a step before creating cancer cell colonies in the site far from the primary tumor. Although the role of miRNA in this process is unknown, it is hypothesized that these molecules may influence cancer cell extravasation. Only two studies have shown that miRNA regulated cancer cell extravasation in breast cancer and melanoma (Valastyan et al., 2009; Penna et al., 2011).

\section{METASTATIC COLONIZATION}

The final step in cancer metastasis is colonization of distant organs by cancer cells and formation of secondary tumors. The circulating tumor cells or cancer cells in the bloodstream show affinity for particular organs (Paget, 1989). This organ-specific targeting is explained by the "seed and soil" hypothesis. The cancer cells are the "seed" and the specific organ microenvironment is the "soil". Metastatic colonization of this microenvironment may be dependent on the ability of cancer cells to proliferate and to adapt to new conditions. Cancer stem cells are the subpopulation of cancer cells characterized by the ability of self-renewal and multipotency, which may aid in the establishment of distant metastases (Dieter et al., 2011). microRNA may regulate the pathways that are required for the phenotype of stem cells. The abnormal level of miRNA was observed in cancer stem cells compared to their non-stem counterpart. In CRC, the expression of miR-328 was down-regulated in SP cells (Xu et al., 2012b). Low miR-328 expression correlated with high SP fraction and miR-328 had an effect on the number of SP cells. The expression of miR-26b was downregulated in human embryonic stem cell line (HUES-17) and in CRC cell line (LoVo) (Ma et al., 2011). Over-expression of miR-26b significantly suppressed cell growth and induction of apoptosis in LoVo cells in vitro and the inhibition of tumor growth in vivo. Since these miRNAs may regulate the stem-cell properties of cancer cells, they may play a role in CRC metastasis. Also, miR-103/107induced down-regulation of DAPK and KLF4 enabling the colonization of CRC cells at a metastatic site, but the exact mechanism of that action is unknown (Chen et al., 2012).

\section{CLINICAL APPLICATION}

Currently, the gold standard for diagnosing patients with an elevated risk of CRC is the non-invasive faecal occult blood test (FOBT), but due to its low sensitivity, patients with a positive result of FOBT are subjected to colonoscopy (Lieberman, 2009). There are a few tests of predictive significance including ColoGuideEx, ColoPrint, Oncotype DX colon cancer assay or OncoDefender-CRC, which are based on the multi-gene expression measurement to distinguish between high and low risk of tumor recurrence (Agesen et al., 2012; Tan \& Tan, 2011; Kelley \& Venook, 2011; Webber et al., 
2010). Their main drawback is that they require CRC tissue samples and thus can be conducted only after surgery or biopsy. Another method for diagnosing patients could be assessment of miRNA level since changes in the expression pattern of miRNA accompany pathogenesis of most human cancers including CRC (Calin \& Croce, 2006; Iorio \& Croce, 2012). microRNA profiling in cancer cells identified miRNA patterns which distinguish between benign and malignant colorectal tumor (Zhang et al., 2012b; Yamashita et al., 2012; Vickers et al., 2012). Moreover, serum, plasma or faecal material may be used as samples containing miRNA. Routine predictive and prognostic CRC biomarkers should be present in non-invasively accessible biological material, specific for the cancer and sensitive enough to assess the course of disease and response to drug treatment. Thus, there is a need for implementation of a sensitive, specific and non-invasive method for CRC prognosis and prediction.

microRNAs may be packed into exosomes and excreted into the bloodstream and other body fluids (Valadi et al., 2007). These extracellular circulating miRNAs are stable and resistant to degradation by nucleases (Turchinovich et al., 2011). The question is whether specific miRNA are secreted to the bloodstream. microRNAs from necrotic or lysed cells were present in the circulation (Wang et al., 2009a). A difference was found between extracellular and intracellular concentration of miRNA, suggesting a selective mechanism(s) for miRNA secretion (Pigati et al., 2010). microRNAs were actively transported outside cells bound to Argonaute proteins (Valadi et al., 2007; Arroyo et al., 2011). Some reports showed that the secreted miRNA population might play a role in communication between cells (Valadi et al., 2007). microRNAs were found in inter alia plasma, serum and faecal matter (Cheng et al., 2011; Wang et al., 2012a; Kalimutho et al., 2011). However, so far only three miRNA biomarkers from these materials are of prognostic value in CRC. The plasma miR-221 level was one of the independent prognostic factors for poor overall survival in CRC patients (Pu et al., 2010). Circulating miR-141 was significantly associated with stage IV CRC (Cheng et al., 2011). High levels of plasma miR-141 predicted poor survival and miR-141 was an independent prognostic factor for advanced CRC. The serum miR-29a level was significantly higher in colorectal liver metastasis patients than in CRC patients thus enabling discrimination between metastatic and non-metastatic tumors (Wang et al., 2012a).

The response to anticancer therapy may differ between patients, thus the personalized approach is needed in such therapy. Mutations and gene expression levels may determine the effectiveness of therapy for a single patient (Garnett et al., 2012; Xu et al., 2012a). Presumably, the miRNA expression level may serve as a predictive biomarker in CRC, but only one study has been reported on the utility of miRNA expression level as a predictive biomarker in CRC. This study concerned miR143, which was frequently down-regulated in CRC and targeted the KRAS oncogene (Pichler et al., 2012). microRNA-143 expression levels served as an independent prognostic biomarker for CRC in $K R A S$-wild-type patients.

Other molecular biomarkers obtainable with non-invasive methods from a blood sample or colonocytes are single nucleotide polymorphisms (SNPs) associated with miRNA. The presence of SNPs in pri-, pre- and mature miRNAs can modulate the expression of genes through alteration of miRNA function. SNPs in pre-miR-423 (rs6505162) and in pre-miR-608 (rs4919510) variant gen- otypes of these SNPs were significantly associated with the recurrence-free survival in CRC (Xing et al., 2012). Additionally, SNPs in pre-miR-423 were associated with overall survival. These effects were significant only in patients receiving chemotherapy. The combined analysis of these two SNPs conferred a 2.84-fold increased risk of recurrence and/or death. A SNP in a lethal-7 (let-7) miRNA complementary site (LCS6) in the KRAS 3'UTR region was prognostic in early-stage CRC (Smits et al., 2011). In patients with $K R A S$-mutated CRC carrying the KRAS-LCS6 variant, there was a better outcome, but in patients with advanced-stage CRC no clear association between that genotype and CRC risk or survival was observed.

The promising clinical application of miRNA seems to be their use aimed at overcoming or reducing drug resistance of CRC cells. ADAM-17 is a protein belonging to a disintegrin and metalloproteinase (ADAM) family of peptidase proteins. This transmembrane enzyme cleaves a variety of transmembrane proteins leading to the activation of growth factor receptor and release of the extracellular domain of the receptor (ectodomain), which regulates the release of cytokines, growth factors and other molecules (Blanchot-Jossic et al., 2005). The increased cleavage of such substrates by ADAM-17 is likely to be associated with tumor spread and growth. High expression of ADAM-17 induced the activation of EGFR (epithelial growth factor receptor) through the shedding of EGFR ligands. ADAM-17 activity was increased in multidrug-resistant (MDR) CRC cells. It was a target for miR-222, which was reported to be downregulated in MDR-CRC (Xu et al., 2012a). Transfection of CRC cells by miR-222 reduced ADAM-17 at the protein and mRNA levels. This suggests that miR-222 could play a role in the development of MDR by modulation of ADAM-17 in CRC. Similar studies were conducted on CRC cells showing stem cell-like properties including insensitiveness to chemotherapy (Xu et al., 2012b). These cells are characterized by the down-regulation of miR-328. Restoration of miR-328 level in CRC stem cell-like cells broke drug resistance. Anticancer treatment based on the introduction of miR-222 or miR-328 to CRC cells may help in MDR overcoming. Apart from miRNA also anti-miRNA may have a potential in anticancer treatment. Knockdown of miRNA-21 was conducted with the locked nucleic acid (LNA) against miR21 (anti-miR-21) in CRC cell lines (Valeri et al., 2010). LNA is a modified RNA nucleotide that has an extra bridge linking the 2'-oxygen and 4'-carbon. High expression of miR-21 in CRC tumors was associated with a reduced expression of the hMSH2 (human mutS homolog 2) protein. miR-21 targeted and down-regulated hMSH2 and hMSH6, mismatch repair (MMR) proteins. Cells that over-expressed miR-21 were less sensitive to 5-fluorouracil (5-FU) treatment, which is typical for cells defective in MMR. Moreover, in a xenograft tumor model miR-21 over-expression reduced the therapeutic efficacy of 5-FU. Transfection with anti-miR-21 increased both hMSH2 and hMSH6 protein expression, but not their mRNA levels.

The introduction of synthetic oligonucleotides: mature miRNA mimics, miRNA precursors or pre-miRNA mimics and others may have a therapeutic effect in the case of loss or down-regulation of tumor suppressor miRNAs. In CRC, miR-34a and miR-199a expression inversely correlated with the Axl protein level (Mudduluru et al., 2011). Axl is a receptor tyrosine kinase that induces proliferation, migration and invasion in cancer. Pre-miR-34a or pre-miR-199a transfection 
inhibited in vitro migration and invasion and, in vivo, reduced the number of liver-metastases. Expression of miR-137 in CRC cell lines was found to correlate inversely with $C d c 42$ (cell division control protein 42 homolog) expression (Liu et al., 2011). Cdc42 belongs to the Rho GTPase family and is found to be upregulated in CRC, where it may play a role in CRC initiation and progression. Ectopic expression of miR137 decreased Cdc42 at the mRNA and protein levels and caused the inhibition of proliferation, induction of G1 cell cycle arrest, and block of invasion of the CRC cells at similar rate as the knockdown of Cdc42. Also, the expression of miR-137 suppressed the direct downstream effector of Cdc42, PAK (p21-activated kinases). However, the introduction of anti-miR-137 led to the opposite effect. In the study conducted on p53-mutated DLD-1 cell line corresponding to Duke's type C, the cells were transfected with a construct that enabled cocistronic expression of the $\mathrm{p} 53$ protein and artificial microRNAs that targeted mRNA of the p21 protein (Idogawa et al., 2009). P21 is an inhibitor of p53-mediated apoptosis. The level of p21 was significantly attenuated following infection with the construct. Also, an increase in the cell population in G1 cell cycle phase, which is indicative of apoptosis, and a significant increase in chemosensitivity of cancer cells to adriamycin (doxorubicin) was noted. The xenograft studies demonstrated that tumor volume was significantly reduced following the direct injection of the construct into the tumor.

\section{SUMMARY}

Deregulation of gene expression accompanies the CRC transformation. It seems that a number of steps of CRC metastasis may be associated with changes of the miRNA expression profile. This constitutes a prerequisite for application of miRNAs as molecular biomarkers for prognosis and prediction in CRC. Apart from changes in miRNA expression pattern in CRC tissue, changes are also observed in the pool of circulating miRNAs. These miRNAs may be considered as a tool for personalized anticancer therapy as they are degradation-resistant, specific for the cancer type, detectable in $10 \mathrm{ng}$ of total RNA and accessible through non-invasive methods. Due to changes in miRNA profile during CRC metastasis and influence of miRNA expression on the phenotype, miRNA may be used in the treatment of CRC. microRNAs may be especially efficient as they target multiple genes of one metabolic pathway. However, regulation of several genes by one miRNA may have severe consequences since it may cause off-target effects producing toxic phenotypes. Anticancer therapy with miRNA is based mainly on the restoration of tumor suppressor genes, inhibition of oncogenes, sensitizing cells to chemotherapy or down-regulating cell stemness. The obstacle to introducing miRNA into clinical use is the delivery of miRNA into the tumor since synthetic miRNA are rapidly degraded by nucleases and poorly taken up by cancer cells. Fortunately, new methods are being developed for targeting cancer cells with miRNA. Viral and non-viral miRNA delivery systems are currently in progress and new synthetic miRNA characterized by increased hybridization affinity, target specificity and resistance to exo- and endonucleases are being introduced. However, miRNA-based therapy and biomarkers are still in their infancy but show great promise in replacement or supplementation of current prognostic and predictive markers and anticancer treatment.

\section{Acknowledgements}

This work was supported by grant 506/812 from the University of Lodz.

\section{REFERENCES}

Agesen TH, Sveen A, Merok MA, Lind GE, Nesbakken A, Skotheim RI, Lothe RA (2012) ColoGuideEx: a robust gene classifier specific for stage II colorectal cancer prognosis. Gut 2 [Epub ahead of print].

Arndt GM, Dossey L, Cullen LM, Lai A, Druker R, Eisbacher M, Zhang C, Tran N, Fan H, Retzlaff K, Bittner A, Raponi M (2009) Characterization of global microRNA expression reveals oncogenic potential of miR-145 in metastatic colorectal cancer. BMC Cancer 9: 374.

Arroyo JD, Chevillet JR, Kroh EM, Ruf IK, Pritchard CC, Gibson DF, Mitchell PS, Bennett CF, Pogosova-Agadjanyan EL, Stirewalt DL, Tait JF, Tewari M (2011) Argonaute2 complexes carry a population of circulating microRNAs independent of vesicles in human plasma. Proc Natl Acad Sci USA 108: 5003-5008.

Asangani IA, Rasheed SA, Nikolova DA, Leupold JH, Colburn NH, Post S, Allgayer H (2008) MicroRNA-21 (miR-21) post-transcriptionally downregulates tumor suppressor Pdcd4 and stimulates invasion, intravasation and metastasis in colorectal cancer. Oncogene 27: 2128-2136.

Bartel DP (2009) MicroRNAs: target recognition and regulatory functions. Cell 136: 215-233.

Bhardwaj A, Singh S, Singh AP (2010) MicroRNA-based Cancer Therapeutics: Big Hope from Small RNAs. Mol Cell Pharmacol 2: 213219.

Blanchot-Jossic F, Jarry A, Masson D, Bach-Ngohou K, Paineau J, Denis MG, Laboisse CL, Mosnier JF (2005) Up-regulated expression of ADAM17 in human colon carcinoma: co-expression with EGFR in neoplastic and endothelial cells. J Pathol 207: 156-163.

Bockhorn M, Jain RK, Munn LL (2007) Active versus passive mechanisms in metastasis: do cancer cells crawl into vessels, or are they pushed? Lancet Oncol 8: 444-448.

Bohnsack MT, Czaplinski K, Görlich D (2004) Exportin 5 is a RanGTP-dependent dsRNA-binding protein that mediates nuclear export of pre-miRNAs. RNA 10: 185-191.

Bonauer A, Carmona G, Iwasaki M, Mione M, Koyanagi M, Fischer A, Burchfield J, Fox H, Doebele C, Ohtani K, Chavakis E, Potente M, Tjwa M, Urbich C, Zeiher AM, Dimmeler S (2009) MicroRNA-92a controls angiogenesis and functional recovery of ischemic tissues in mice. Science 324: 1710-1713.

Boardman LA (2009) Overexpression of MACC1 leads to downstream activation of $\mathrm{HGF} / \mathrm{MET}$ and potentiates metastasis and recurrence of colorectal cancer. Genome Med 1: 36.

Calin GA, Croce CM (2006) MicroRNA-cancer connection: the beginning of a new tale. Cancer Res 66: 7390-7394.

Chang KH, Miller N, Kheirelseid EA, Lemetre C, Ball GR, Smith MJ, Regan M, McAnena OJ, Kerin MJ (2011) MicroRNA signature analysis in colorectal cancer: identification of expression profiles in stage II tumors associated with aggressive disease. Int J Colorectal Dis 26: $1415-1422$.

Chavakis E, Dimmeler S (2002) Regulation of endothelial cell survival and apoptosis during angiogenesis. Arterioscler Thromb V asc Biol 22: 887-893.

Chen RH, Chen HY, Lin YM, Chung HC, Lang YD, Lin CJ, Huang J, Wang WC, Lin FM, Chen Z, Huang HD, Shyy JY, Liang JT (2012) miR-103/107 promote metastasis of colorectal cancer by targeting the metastasis suppressors DAPK and KLF4. Cancer Res 72: 36313641.

Cheng H, Zhang L, Cogdell DE, Zheng H, Schetter AJ, Nykter M, Harris CC, Chen K, Hamilton SR, Zhang W (2011) Circulating plasma miR-141 is a novel biomarker for metastatic colon cancer and predicts poor prognosis. PLoS One 6: e17745.

Dentelli P, Rosso A, Orso F, Olgasi C, Taverna D, Brizzi MF (2010) microRNA-222 controls neovascularization by regulating signal transducer and activator of transcription 5A expression. Arterioscler Thromb V asc Biol 30: 1562-1568.

Dews M, Homayouni A, Yu D, Murphy D, Sevignani C, Wentzel E, Furth EE, Lee WM, Enders GH, Mendell JT, Thomas-Tikhonenko A (2006) Augmentation of tumor angiogenesis by a Myc-activated microRNA cluster. Nat Genet 38: 1060-1065.

Dieter SM, Ball CR, Hoffmann CM, Nowrouzi A, Herbst F, Zavidij O, Abel U, Arens A, Weichert W, Brand K, Koch M, Weitz J, Schmidt M, von Kalle C, Glimm H (2011) Distinct types of tumor-initiating cells form human colon cancer tumors and metastases. Cell Stem Cell 9: $357-365$. 
Dobrucki LW, Tsutsumi Y, Kalinowski L, Dean J, Gavin M, Sen S, Mendizabal M, Sinusas AJ, Aikawa R (2010) Analysis of angiogenesis induced by local IGF-1 expression after myocardial infarction using microSPECT-CT imaging. J Mol Cell Cardiol 48: 1071-1079.

Faltejskova P, Besse A, Sevcikova S, Kubiczkova L, Svoboda M, Smarda J, Kiss I, Vyzula R, Slaby O (2012) Clinical correlations of miR-21 expression in colorectal cancer patients and effects of its inhibition on DLD1 colon cancer cells. Int J Colorectal Dis [Epub ahead of print].

Fasanaro P, D'Alessandra Y, Di Stefano V, Melchionna R, Romani S, Pompilio G, Capogrossi MC, Martelli F (2008) MicroRNA-210 modulates endothelial cell response to hypoxia and inhibits the receptor tyrosine kinase ligand Ephrin-A3. J Biol Chem 283: $15878-$ 15883.

Fassan M, Pizzi M, Giacomelli L, Mescoli C, Ludwig K, Pucciarelli S, Rugge M (2011) PDCD4 nuclear loss inversely correlates with miR21 levels in colon carcinogenesis. Virchows Arch 458: 413-419.

Ferlay J, Shin HR, Bray F, Forman D, Mathers C, Parkin DM (2010) GLOBOCAN 2008 v1.2: Cancer incidence and mortality worldwide: IARC CancerBase No. 10. Lyon (France): IARC Press.

Fish JE, Santoro MM, Morton SU, Yu S, Yeh RF, Wythe JD, Ivey KN, Bruneau BG, Stainier DY, Srivastava D (2008) miR-126 regulates angiogenic signaling and vascular integrity. Dev Cell 15: $272-$ 284.

Fu J, Tang W, Du P, Wang G, Chen W, Li J, Zhu Y, Gao J, Cui L (2012) Identifying MicroRNA-mRNA regulatory network in colorectal cancer by a combination of expression profile and bioinformatics analysis. BMC Syst Biol 6: 68 [Epub ahead of print].

Garnett MJ, Edelman EJ, Heidorn SJ, Greenman CD, Dastur A, Lau KW, Greninger P, Thompson IR, Luo X, Soares J, Liu Q, Iorio F, Surdez D, Chen L, Milano RJ, Bignell GR, Tam AT, Davies $\mathrm{H}$, Stevenson JA, Barthorpe S, Lutz SR, Kogera F, Lawrence K, McLaren-Douglas A, Mitropoulos X, Mironenko T, Thi H, Richardson L, Zhou W, Jewitt F, Zhang T, O'Brien P, Boisvert JL, Price S, Hur W, Yang W, Deng X, Butler A, Choi HG, Chang JW, Baselga J, Stamenkovic I, Engelman JA, Sharma SV, Delattre O, SaezRodriguez J, Gray NS, Settleman J, Futreal PA, Haber DA, Stratton MR, Ramaswamy S, McDermott U, Benes CH (2012) Systematic identification of genomic markers of drug sensitivity in cancer cells. Nature 483: 570-575.

Ghosh G, Subramanian IV, Adhikari N, Zhang X, Joshi HP, Basi D, Chandrashekhar YS, Hall JL, Roy S, Zeng Y, Ramakrishnan S (2010) Hypoxia-induced microRNA-424 expression in human endothelial cells regulates HIF-alpha isoforms and promotes angiogenesis. J Clin Invest 120: 4141-4154.

Gregory RI, Chendrimada TP, Cooch N, Shiekhattar R (2005) Human RISC couples microRNA biogenesis and posttranscriptional gene silencing. Cell 123: 631-640.

Guo C, Sah JF, Beard L, Willson JK, Markowitz SD, Guda K (2008) The noncoding RNA, miR-126, suppresses the growth of neoplastic cells by targeting phosphatidylinositol 3-kinase signaling and is frequently lost in colon cancers. Genes Chromosomes Cancer 47: 939-946.

Guo ST, Jiang CC, Wang GP, Li YP, Wang CY, Guo XY, Yang RH, Feng Y, Wang FH, Tseng HY, Thorne RF, Jin L, Zhang XD (2012) MicroRNA-497 targets insulin-like growth factor 1 receptor and has a tumour suppressive role in human colorectal cancer. Oncogene [Epub ahead of print].

$\mathrm{Ha}$ TY (2011) microRNAs in Human Diseases: From Cancer to Cardiovascular Disease. Immune Netw 11: 135-154.

Han J, Lee Y, Yeom KH, Kim YK, Jin H, Kim VN (2004) The Drosha-DGCR8 complex in primary microRNA processing. Genes Dev 18: 3016-3027.

Harris TA, Yamakuchi M, Ferlito M, Mendell JT, Lowenstein CJ (2008) MicroRNA-126 regulates endothelial expression of vascular cell adhesion molecule 1. Proc Natl Acad Sci USA 105: 1516-1521.

Huang Z, Huang D, Ni S, Peng Z, Sheng W, Du X (2010) Plasma microRNAs are promising novel biomarkers for early detection of colorectal cancer. Int J Cancer 127: 118-126.

Humphreys KJ, Cobiac L, Le Leu RK, Van der Hoek MB, Michael MZ (2012) Histone deacetylase inhibition in colorectal cancer cells reveals competing roles for members of the oncogenic miR-17-92 cluster. Mol Carcinog [Epub ahead of print].

Hur K, Toiyama Y, Takahashi M, Balaguer F, Nagasaka T, Koike J, Hemmi H, Koi M, Boland CR, Goel A (2012) MicroRNA-200c modulates epithelial-to-mesenchymal transition (EMT) in human colorectal cancer metastasis. Gut [Epub ahead of print].

Idogawa M, Sasaki Y, Suzuki H, Mita H, Imai K, Shinomura Y, Tokino $T$ (2009) A single recombinant adenovirus expressing p53 and p21-targeting artificial microRNAs efficiently induces apoptosis in human cancer cells. Clin Cancer Res 15: 3725-3732.

Iorio MV, Croce CM (2012) MicroRNA dysregulation in cancer: diagnostics, monitoring and therapeutics. A comprehensive review. EMBO Mol Med 4: 143-159.

Jain RK (2005) Normalization of tumor vasculature: an emerging concept in antiangiogenic therapy. Science 307: 58-62.
Kalimutho M, Del Vecchio Blanco G, Di Cecilia S, Sileri P, Cretella M, Pallone F, Federici G, Bernardini S (2011) Differential expression of miR-144* as a novel fecal-based diagnostic marker for colorectal cancer. I Gastroenterol 46: 1391-1402.

Kanaan Z, Rai SN, Eichenberger MR, Barnes C, Dworkin AM, Weller C, Cohen E, Roberts H, Keskey B, Petras RE, Crawford NP, Galandiuk S (2012) Differential microRNA expression tracks neoplastic progression in inflammatory bowel disease-associated colorectal cancer. Hum Mutat 33: 551-560.

Kelley RK, Venook AP (2011) Prognostic and predictive markers in stage II colon cancer: is there a role for gene expression profiling? Clin Colorectal Cancer 10: 73-80.

Kern HB, Niemeyer BF, Parrish JK, Kerr CA, Yaghi NK, Prescott JD, Gutierrez-Hartmann A, Jedlicka P (2012) Control of microRNA-21 expression in colorectal cancer cells by oncogenic epidermal growth factor/ras signaling and ets transcription factors. DNA Cell Biol 31: 1403-1411.

Koga Y, Yasunaga M, Takahashi A, Kuroda J, Moriva Y, Akasu T, Fujita S, Yamamoto S, Baba H, Matsumura Y (2010) MicroRNA expression profiling of exfoliated colonocytes isolated from feces for colorectal cancer screening. Cancer Prev Res (Phila) 11: 1435-1442.

Lee Y, Ahn C, Han JJ, Choi H, Kim J, Yim J, Lee J, Provost P, Radmark O, Kim S, Kim VN (2003) The nuclear RNase III Drosha initiates microRNA processing. Nature 425: 415-419.

Lee Y, Kim M, Han J, Yeom KH, Lee S, Baek SH, Kim VN (2004) MicroRNA genes are transcribed by RNA polymerase II. EMBO J 23: 4051-4060.

Lewis BP, Burge CB, Bartel DP (2005) Conserved seed pairing, often flanked by adenosines, indicates that thousands of human genes are microRNA targets. Cell 120: 15-20.

Lieberman DA (2009) Clinical practice. Screening for colorectal cancer. N Engl J Med 361: 1179-1187.

Liu M, Lang N, Qiu M, Xu F, Li Q, Tang Q, Chen J, Chen X, Zhang S, Liu Z, Zhou J, Zhu Y, Deng Y, Zheng Y, Bi F (2011) miR-137 targets Cdc42 expression, induces cell cycle G1 arrest and inhibits invasion in colorectal cancer cells. Int J Cancer 128: 1269-1279.

Lu LF, Liston A (2009) MicroRNA in the immune system, microRNA as an immune system. Immunology 127: 291-298.

Ma YL, Zhang P, Wang F, Moyer MP, Yang J, Liu ZH, Peng JY, Chen HQ, Zhou YK, Liu WJ, Qin HL (2011) Human embryonic stem cells and metastatic colorectal cancer cells shared the common endogenous human microRNA-26b. J Cell Mol Med 15: 1941-1954.

Mudduluru G, Ceppi P, Kumarswamy R, Scagliotti GV, Papotti M, Allgayer H (2011) Regulation of Axl receptor tyrosine kinase expression by miR-34a and miR-199a/b in solid cancer. Oncogene 30: 2888-2899.

Muniyappa MK, Dowling P, Henry M, Meleady P, Doolan P, Gammell P, Clynes M, Barron N (2009) MicroRNA-29a regulates the expression of numerous proteins and reduces the invasiveness and proliferation of human carcinoma cell lines. Eur J Cancer 45: 3104-3118.

Ono H, Imoto I, Kozaki K, Tsuda H, Matsui T, Kurasawa Y, Muramatsu T, Sugihara K, Inazawa J (2012) SIX1 promotes epithelialmesenchymal transition in colorectal cancer through ZEB1 activation. Oncogene [Epub ahead of print].

Ota T, Doi K, Fujimoto T, Tanaka Y, Ogawa M, Matsuzaki H, Kuroki M, Miyamoto S, Shirasawa S, Tsunoda T (2012) KRAS Up-regulates the Expression of miR-181a, miR-200c and miR-210 in a Threedimensional-specific Manner in DLD-1 Colorectal Cancer Cells. Anticancer Res 32: 2271-2275.

Paget S (1989) The distribution of secondary growths in cancer of the breast. Cancer Metastasis Rev 8: 98-101.

Penna E, Orso F, Cimino D, Tenaglia E, Lembo A, Quaglino E, Poliseno L, Haimovic A, Osella-Abate S, De Pittà C, Pinatel E, Stadler MB, Provero P, Bernengo MG, Osman I, Taverna D (2011) MicroRNA-214 contributes to melanoma tumour progression through suppression of TFAP2C. EMBO J 30: 1990-2007.

Pichler M, Winter E, Stotz M, Eberhard K, Samonigg H, Lax S, Hoefler G (2012) Down-regulation of KRAS-interacting miRNA-143 predicts poor prognosis but not response to EGFR-targeted agents in colorectal cancer. Br I Cancer 106: 1826-1832.

Pigati L, Yaddanapudi SC, Iyengar R, Kim DJ, Hearn SA, Danforth D, Hastings ML, Duelli DM (2010) Selective release of microRNA species from normal and malignant mammary epithelial cells. PLoS One 5: e13515.

Poliseno L, Tuccoli A, Mariani L, Evangelista M, Citti L, Woods K, Mercatanti A, Hammond S, Rainaldi G (2006) MicroRNAs modulate the angiogenic properties of HUVECs. Blood 108: 3068-3071.

Pu XX, Huang GL, Guo HQ, Guo CC, Li H, Ye S, Ling S, Jiang L, Tian Y, Lin TY (2010) Circulating miR-221 directly amplified from plasma is a potential diagnostic and prognostic marker of colorectal cancer and is correlated with p53 expression. J Gastroenterol Hepatol 25: 1674-1680.

Rodriguez S, Huynh-Do U (2012) The Role of PTEN in Tumor Angiogenesis. I Oncol 2012: 141236.

Schepeler T, Holm A, Halvey P, Nordentoft I, Lamy P, Riising EM, Christensen LL, Thorsen K, Liebler DC, Helin K, Orntoft TF, An- 
dersen CL (2012) Attenuation of the beta-catenin/TCF4 complex in colorectal cancer cells induces several growth-suppressive microRNAs that target cancer promoting genes. Oncogene 31: 2750-2760.

Slaby O, Svoboda M, Fabian P, Smerdova T, Knoflickova D, Bednarikova M, Nenutil R, Vyzula R (2007) Altered expression of miR21, miR-31, miR-143 and miR-145 is related to clinicopathologic features of colorectal cancer. Oncology 72: 397-402.

Smits KM, Paranjape T, Nallur S, Wouters KA, Weijenberg MP, Schouten LJ, van den Brandt PA, Bosman FT, Weidhaas JB, van Engeland M (2011) A let-7 microRNA SNP in the KRAS 3'UTR is prognostic in early-stage colorectal cancer. Clin Cancer Res 17: $7723-7731$.

Suárez Y, Fernández-Hernando C, Pober JS, Sessa WC (2007) Dicer dependent microRNAs regulate gene expression and functions in human endothelial cells. Circ Res 100: 1164-1173.

Sun K, Wang W, Zeng JJ, Wu CT, Lei ST, Li GX (2011) microRNA-221 inhibits CDKN1C/p57 expression in human colorectal carcinoma. Acta Pharmacol Sin 32: 375-384.

Sundaram P, Hultine S, Smith LM, Dews M, Fox JL, Biyashev D, Schelter JM, Huang Q, Cleary MA, Volpert OV, Thomas-Tikhonenko A (2011) p53-responsive miR-194 inhibits thrombospondin-1 and promotes angiogenesis in colon cancers. Cancer Res 71: 74907501.

Tan IB, Tan P (2011) Genetics: an 18-gene signature (ColoPrint $\left.{ }^{\circledR}\right)$ for colon cancer prognosis. Nat Rev Clin Oncol 8: 131-133.

Tanzer A, Stadler PF (2004) Molecular evolution of a microRNA cluster. J Mol Biol 339: 327-335.

Turchinovich A, Weiz L, Langheinz A, Burwinkel B (2011) Characterization of extracellular circulating microRNA. Nucleic Acids Res 39: 7223-7233.

Vaira V, Faversani A, Dohi T, Montorsi M, Augello C, Gatti S, Coggi G, Altieri DC, Bosari S (2012) miR-296 regulation of a cell polarity-cell plasticity module controls tumor progression. Oncogene 31: 27-38.

Valadi H, Ekstrom K, Bossios A, Sjostrand M, Lee JJ, Lotvall JO (2007) Exosome-mediated transfer of mRNAs and microRNAs is a novel mechanism of genetic exchange between cells. Nat Cell Biol 9: 654-659.

Valastyan S, Reinhardt F, Benaich N, Calogrias D, Szász AM, Wang ZC, Brock JE, Richardson AL, Weinberg RA (2009) A pleiotropically acting microRNA, miR-31, inhibits breast cancer metastasis. Cell 137: 1032-1046.

Valeri N, Gasparini P, Braconi C, Paone A, Lovat F, Fabbri M, Sumani KM, Alder H, Amadori D, Patel T, Nuovo GJ, Fishel R, Croce CM (2010) MicroRNA-21 induces resistance to 5-fluorouracil by down-regulating human DNA MutS homolog 2 (hMSH2). Proc Natl Acad Sci USA 107: 21098-21103.

Vicinus B, Rubie C, Faust SK, Frick VO, Ghadjar P, Wagner M, Graeber S, Schilling MK (2012) miR-21 functionally interacts with the 3'UTR of chemokine CCL20 and down-regulates CCL20 expression in miR-21 transfected colorectal cancer cells. Cancer Lett 316: 105-112.

Vickers MM, Bar J, Gorn-Hondermann I, Yarom N, Daneshmand M, Hanson JE, Addison CL, Asmis TR, Jonker DJ, Maroun J, Lorimer IA, Goss GD, Dimitroulakos J (2012) Stage-dependent differential expression of microRNAs in colorectal cancer: potential role as markers of metastatic disease. Clin Exp Metastasis 29: 123-132.
Wang S, Aurora AB, Johnson BA, Qi X, McAnally J, Hill JA, Richardson JA, Bassel-Duby R, Olson EN (2008) The endothelial- specific microRNA miR-126 governs vascular integrity and angiogenesis. Dev Cell 15: 261-271.

Wang K, Zhang S, Marzolf B, Troisch P, Brightman A, Hu Z, Hood LE, Galas DJ (2009a) Circulating microRNAs, potential biomarkers for drug-induced liver injury. Proc Natl Acad Sci USA 106: 44024407.

Wang P, Zou F, Zhang X, Li H, Dulak A, Tomko RJ Jr, Lazo JS, Wang Z, Zhang L, Yu J (2009b) MicroRNA-21 negatively regulates Cdc25A and cell cycle progression in colon cancer cells. Cancer Res 69: 8157-8165.

Wang CJ, Stratmann J, Zhou ZG, Sun XF (2010) Suppression of microRNA-31 increases sensitivity to $5-\mathrm{FU}$ at an early stage, and affects cell migration and invasion in HCT-116 colon cancer cells. BMC Cancer 10: 616.

Wang LG, Gu J (2012a) Serum microRNA-29a is a promising novel marker for early detection of colorectal liver metastasis. Cancer Epidemiol 36: e61-7.

Wang X, Wang J, Ma H, Zhang J, Zhou X (2012b) Downregulation of miR-195 correlates with lymph node metastasis and poor prognosis in colorectal cancer. Med Oncol 29: 919-927.

Webber EM, Lin JS, Evelyn P Whitlock (2010) Oncotype DX tumor gene expression profiling in stage II colon cancer. Application: prognostic, risk prediction. PLoS Curr 2: RRN1177.

Xing J, Wan S, Zhou F, Qu F, Li B, Myers RE, Fu X, Palazzo JP, He X, Chen Z, Yang H (2012) Genetic polymorphisms in pre-microRNA genes as prognostic markers of colorectal cancer. Cancer Epidemiol Biomarkers Prev 21: 217-227.

Xu K, Liang X, Shen K, Sun L, Cui D, Zhao Y, Tian J, Ni L, Liu J (2012a) miR-222 modulate multidrug resistance in human colorectal carcinoma by down-regulating ADAM-17. Exp Cell Res 18: 21682177.

Xu XT, Xu Q, Tong JL, Zhu MM, Nie F, Chen X, Xiao SD, Ran ZH (2012b) MicroRNA expression profiling identifies miR-328 regulates cancer stem cell-like SP cells in colorectal cancer. Br J Cancer 106: 1320-1330

Yamashita S, Yamamoto H, Mimori K, Nishida N, Takahashi H, Haraguchi N, Tanaka F, Shibata K, Sekimoto M, Ishii H, Doki Y, Mori M (2012) MicroRNA-372 is associated with poor prognosis in colorectal cancer. Oncology 82: 205-212.

Zhang J, Xiao Z, Lai D, Sun J, He C, Chu Z, Ye H, Chen S, Wang $\mathrm{J}$ (2012a) miR-21, miR-17 and miR-19a induced by phosphatase of regenerating liver-3 promote the proliferation and metastasis of colon cancer. Br J Cancer 107: 352-359.

Zhang G, Xia S, Tian H, Liu Z, Zhou T (2012b) Clinical significance of miR-22 expression in patients with colorectal cancer. Med Oncol [Epub ahead of print].

Zhao W, Hisamuddin IM, Nandan MO, Babbin BA, Lamb NE, Yang VW (2004) Identification of Krüppel-like factor 4 as a potential tumor suppressor gene in colorectal cancer. Oncogene 23: 395-402.

Zheng T, Wang J, Chen X, Liu L (2010) Role of microRNA in anticancer drug resistance. Int J Cancer 126: 2-10.

Zhu N, Zhang D, Chen S, Liu X, Lin L, Huang X, Guo Z, Liu J, Wang Y, Yuan W, Qin Y (2011) Endothelial enriched microRNAs regulate angiotensin II-induced endothelial inflammation and migration. Atherosclerosis 215: 286-293. 